\title{
DHA ameliorates MeHg-induced PC12 cell apoptosis by inhibiting the ROS/JNK signaling pathway
}

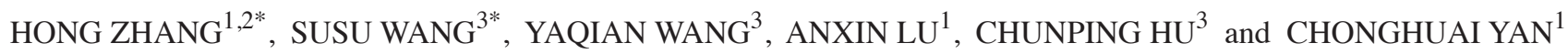 \\ ${ }^{1}$ Ministry of Education-Shanghai Key Laboratory of Children's Environmental Health, Xinhua Hospital Affiliated to \\ Shanghai Jiao Tong University School of Medicine, Shanghai 200092; ${ }^{2}$ State Key Laboratory of Bioreactor Engineering and \\ Shanghai Key Laboratory of New Drug Design, School of Pharmacy, East China University of Science and Technology, \\ Shanghai 200237; ${ }^{3}$ School of Public Health, Shanghai Jiao Tong University, Shanghai 200025, P.R. China
}

Received December 31, 2020; Accepted March 24, 2021

DOI: $10.3892 / \mathrm{mmr} .2021 .12197$

\begin{abstract}
Recent studies have reported that methylmercury $(\mathrm{MeHg})$ induces neuronal apoptosis, which is accompanied by abnormal neurological development. Despite the important role of docosahexaenoic acid (DHA) in maintaining the structure and function of the brain, as well as improving neuronal apoptosis induced by $\mathrm{MeHg}$, the exact mechanism remains unknown. The present study hypothesized that the reactive oxygen species (ROS)-mediated JNK signaling pathway may be associated with the protective effect of DHA against $\mathrm{MeHg}$-induced PC12 cell apoptosis. Cell Counting Kit-8, TUNEL staining, flow cytometry, ROS detection, PCR and western blot analysis were performed. The results demonstrated that $\mathrm{MeHg}$ inhibited the activity of PC12 cells, causing oxidative damage and promoting apoptosis; however, DHA significantly attenuated this effect. Mechanistic studies revealed that $\mathrm{MeHg}$ increased intracellular ROS levels and JNK protein phosphorylation, and decreased the expression levels of the anti-apoptotic protein Bcl-2, whereas DHA reduced ROS levels and JNK phosphorylation, and increased $\mathrm{Bcl}-2$ expression. In addition, the ROS inhibitor N-acetyl-l-cysteine (NAC) was used to verify the experimental results. After pretreatment with NAC, expression levels of Bcl-2, Bax, phosphorylated-JNK and JNK were assessed. Bcl-2 protein expression was increased and the Bcl-2/Bax ratio was increased. Moreover, the high expression levels of phosphorylated-JNK induced by MeHg were significantly decreased. Based on the aforementioned results,
\end{abstract}

Correspondence to: Dr Chonghuai Yan, Ministry of Education-Shanghai Key Laboratory of Children's Environmental Health, Xinhua Hospital Affiliated to Shanghai Jiao Tong University School of Medicine, 1665 Kongjiang Road, Shanghai 200092, P.R. China

E-mail: yanchonghuai@xinhuamed.com.cn

${ }^{*}$ Contributed equally

Key words: docosahexaenoic acid, methylmercury, apoptosis, reactive oxygen species, JNK pathway the present study indicated that the effects of DHA against MeHg-induced PC12 cell apoptosis may be mediated via the ROS/JNK signaling pathway.

\section{Introduction}

Epidemiological studies have reported that global methylmercury $(\mathrm{MeHg})$ pollution has become increasingly serious in recent years and humans are suffering from the effects of $\mathrm{MeHg}$, which has become a concern for several countries (1). The development of industry and agriculture; the discharge of wastewater, residue and exhaust gas in the process of smelting mercury ores; the combustion of fossil fuel; and the irresponsible use of medical devices, such as use of amalgam as filling material have led to increasingly serious environmental mercury pollution $(2,3)$. Moreover, mercury released into the environment can be converted into $\mathrm{MeHg}$ under certain conditions, such as transformation by aquatic microorganisms, thereby becoming enriched in the aquatic food chain. Once food containing $\mathrm{MeHg}$ is consumed, $\mathrm{MeHg}$ derivatives are formed and accumulate in the body, particularly in the brain, severely affecting human health (4).

The toxic effects of MeHg have been characterized by a long incubation period before symptoms appear in humans. The main symptoms include blurred vision, weight loss, ataxia and neurodevelopmental abnormalities (5). In addition, $\mathrm{MeHg}$ has been reported to serve an important role in early fetal neurodevelopment. It has been reported that the brain $\mathrm{MeHg}$ content of exposed individuals may be 3-6 times higher compared with that in the blood (6). Furthermore, maternal exposure to $\mathrm{MeHg}$ from the consumption of fish and seafood may have irreversible effects on the neurobehavioral development of children, including cognitive impairment, memory impairment and motor developmental abnormalities $(7,8)$.

It was recently demonstrated that the neurotoxicity produced by $\mathrm{MeHg}$ is closely associated with cell apoptosis, and oxidative stress induced by reactive oxygen species (ROS) is the most likely predisposing factor (9). As a secondary messenger, ROS serve a dual role in the body. Stable physiological ROS levels can suppress harmful cellular processes; however, high concentrations of ROS can cause cell apoptosis 
and death (10). A previous study reported that excessive ROS may directly damage DNA and activate the MAPK signaling pathway, initiate mitochondria-related apoptosis and depolarize the mitochondrial membrane, thus damaging the integrity of the mitochondrial membrane (11). Eventually, cytochrome $c$ may be released into the cytoplasm from the mitochondrial intermembrane space, thereby activating caspases to induce cell apoptosis (12).

JNK, also known as stress-activated protein kinase, is a member of the MAPK superfamily, and is involved in various stress responses, particularly oxidative damage $(13,14)$. It has previously been reported that $\mathrm{MeHg}$ can increase intracellular ROS levels, causing changes in glutathione content and lipid peroxidation, resulting in oxidative damage (9). Therefore, $\mathrm{MeHg}$-induced apoptosis may be associated with activation of the ROS-regulated JNK signaling pathway.

Docosahexaenoic acid (DHA) is an essential n-3 long-chain polyunsaturated fatty acid that is mainly present in the brain, and is involved in neurotransmitter pathways, synaptic transmission and signal transduction (15). DHA is essential for the development of the nervous system in children. Epidemiological studies have identified that the presence of more n-3 unsaturated fatty acids may promote in utero fetal neurodevelopment in women who are exposed to low levels of $\mathrm{MeHg}(16,17)$. In addition, consumption of certain fish, such as salmon, with a higher DHA content may effectively decrease the neurotoxicity of $\mathrm{MeHg}$ in children (18).

Previous studies have revealed that DHA can effectively reduce $\mathrm{MeHg}$-induced oxidative damage and inhibit apoptosis in different types of cells (19-21). Kaur et al (20) reported that DHA pretreatment effectively reduced cell-associated $\mathrm{MeHg}$ and the prooxidant response from $\mathrm{MeHg}$ in cerebellar astrocytes and neurons, thus supporting the hypothesis that fish-derived nutrients offer possible neuroprotection from $\mathrm{MeHg}$. However, there is limited research on the mechanism underlying the effects of DHA against $\mathrm{MeHg}$-induced apoptosis. Therefore, as PC12 cells are widely used in neurological research, a $\mathrm{MeHg}$-induced PC12 cell apoptosis model was established in the present study to further examine the anti-apoptotic mechanism of DHA against $\mathrm{MeHg}$ based on regulation of the JNK signaling pathway.

\section{Materials and methods}

Materials. MeHg chloride and cis-4,7,10,13,16,19-DHA were obtained from Sigma-Aldrich (Merck KGaA). Cell Counting Kit-8 (CCK-8), TUNEL Apoptosis Assay kit, Annexin V-FITC Apoptosis Assay kit, Reactive Oxygen Assay kit, cell lysis buffer for western blotting and N-acetyl-1-cysteine (NAC) were purchased from Beyotime Institute of Biotechnology. Antibodies against Bax (cat. no. 2772S), JNK (cat. no. 9252S) and phosphorylated (p)JNK (cat. no. 4668S) were purchased from Cell Signaling Technology, Inc. Anti-Bcl-2 (cat. no. AB112) was purchased from Beyotime Institute of Biotechnology and anti-GAPDH (cat. no. 30202ES40) was purchased from Shanghai Yeasen Biotechnology Co., Ltd. The gene-specific primers were designed by Sangon Biotech Co., Ltd.
Cell culture. The PC12 rat pheochromocytoma cell line (serial no. TCR8) was purchased from The Cell Bank of Type Culture Collection of The Chinese Academy of Sciences. The purchased cells were commercialized poorly differentiated PC12 cells. The cells were incubated in a $60-\mathrm{mm}$ culture dish in DMEM (HyClone; Cytiva) supplemented with 5\% horse serum (Sigma-Aldrich; Merck KGaA), 105\% FBS (Sigma-Aldrich; Merck $\mathrm{KGaA}$ ) and $100 \mathrm{U} / \mathrm{ml}$ penicillin-streptomycin in a humidified atmosphere containing $55 \% \mathrm{CO}_{2} / 955 \%$ air at $37^{\circ} \mathrm{C}$.

Cell viability assay. The CCK-8 reagent was applied to evaluate the viability ability of cells. The cells were treated with $\operatorname{MeHg}(1.25,2.5,5,10$ and $20 \mu \mathrm{mol} / \mathrm{l})$ for 24,48 and $72 \mathrm{~h}$ in a $55 \% \mathrm{CO}_{2}$ incubator at $37^{\circ} \mathrm{C}$, and with different concentrations of DHA $(5,10,20,40$ and $80 \mu \mathrm{mol} / \mathrm{l})$ for $24 \mathrm{~h}$ in a $55 \% \mathrm{CO}_{2}$ incubator at $37^{\circ} \mathrm{C}$ to screen for the suitable drug treatment concentration. In addition, to evaluate the protective effect of DHA against $\mathrm{MeHg}$-induced damage in PC12 cells, the cells pretreated with DHA $(5,10,20,40$ and $80 \mu \mathrm{mol} / \mathrm{l})$ for $24 \mathrm{~h}$ were treated with $\mathrm{MeHg}(2.5 \mu \mathrm{mol} / \mathrm{l})$ for $48 \mathrm{~h}$. After treatment, $\mathrm{PC} 12$ cells were cultured in a $55 \% \mathrm{CO}_{2}$ incubator at $37^{\circ} \mathrm{C}$, then incubated with $105 \% \mathrm{CCK}-8$ reagent for $1 \mathrm{~h}$ at $37^{\circ} \mathrm{C}$. The optical density of PC12 cells was measured at a wavelength of $450 \mathrm{~nm}$ using a microplate reader. A cell growth curve was drawn with GraphPad Prism 5 (GraphPad Software, Inc.).

TUNEL staining assay. A TUNEL apoptosis detection kit was used to observe cell apoptosis under a fluorescence microscope. Firstly, cells were grown on culture plates until they reached $805 \%$ confluence and were then treated with DHA followed by $\mathrm{MeHg}$. Cells were washed with PBS and incubated with the $10 \%$ TUNEL solution at $37^{\circ} \mathrm{C}$ in the dark for $60 \mathrm{~min}$. The samples were immediately observed under a fluorescence microscope, where the excitation wavelength was 450-500 $\mathrm{nm}$ and the emission wavelength range was $515-565 \mathrm{~nm}$. Green fluorescence represented apoptotic cells. In addition, nuclei were stained by $100 \mathrm{ng} / \mathrm{ml}$ DAPI (Beyotime Institute of Biotechnology) for $5 \mathrm{~min}$ at $25^{\circ} \mathrm{C}$.

Flow cytometric analysis of apoptosis. A total of $1 \times 10^{5} \mathrm{PC} 12$ cells were added to $100 \mu \mathrm{l}$ binding buffer for $20 \mathrm{~min}$ at $25^{\circ} \mathrm{C}$ following centrifugation at $1,000 \mathrm{x}$ g for $5 \mathrm{~min}$ at $25^{\circ} \mathrm{C}$ and were then added to the Annexin V-FITC and PI mixture, with separate Annexin V-FITC and PI control tubes and an unstained tube. Finally, each sample tube was placed on ice in the dark for $20 \mathrm{~min}$, and $500 \mu \mathrm{l} 1 \mathrm{X}$ binding buffer was added. The samples were analyzed on a LSR Fortessa flow cytometer (BD Biosciences) to detect the apoptotic rate within $30 \mathrm{~min}$, and the upper- and lower-right quadrants show apoptotic cells with FlowJo V10.0.7 (BD Biosciences). The position of the gates of other groups was relative to the control plot in the flow cytometric analysis.

Assessment of ROS. Accumulation of intracellular ROS was detected using the peroxide-sensitive fluorescent probe DCFH-DA. PC12 cells $\left(1 \times 10^{5}\right)$ were cultured for $48 \mathrm{~h}$, after which $\mathrm{MeHg}$ and DHA were added to the culture media. At the end of the treatment, the cells were incubated with $10 \mu \mathrm{mol} / \mathrm{l}$ DCFH-DA for $40 \mathrm{~min}$ at $37^{\circ} \mathrm{C}$. Fluorescence detection was performed using a fluorescence microplate reader at an 
excitation wavelength of $488 \mathrm{~nm}$ and an emission wavelength of $525 \mathrm{~nm}$, in order to determine the generation of ROS.

Western blot analysis. After treatment for the indicated duration, the cells were washed three times with cold PBS and lysed. Total cytoplasmic and nuclear protein was collected using cell lysis buffer for western blotting, according to the manufacturer's instructions. The protein concentration was measured using a BCA assay. Equal amounts of protein $(25 \mu \mathrm{g})$ were separated by $10 \%$ SDS-PAGE, followed by transfer to PVDF membranes. The membranes were blocked in TBS containing $55 \%$ skimmed milk and $0.15 \%$ Tween-20 at $25^{\circ} \mathrm{C}$ for $1 \mathrm{~h}$, and then incubated with primary antibodies against Bcl-2 (1:1,000), Bax (1:1,000), JNK (1:1,000), pJNK (1:1,000) and GAPDH $(1: 10,000)$ at $4^{\circ} \mathrm{C}$ overnight. Anti-GAPDH antibody was selected as an internal reference. Subsequently, the membranes were washed with TBS and incubated with HRP-labeled secondary antibodies (1:1,000; cat. no. A0208; Beyotime Institute of Biotechnology) at room temperature for $1 \mathrm{~h}$. Finally, the blots were visualized using ECL (BeyoECL Moon; cat. no. P0018FS; Beyotime Institute of Biotechnology) and the results were analyzed using Image Lab (5.2.1; Bio-Rad Laboratories, Inc.).

Reverse transcription-quantitative $(R T-q) P C R$. Total RNA was isolated from PC12 cells using TRIzol ${ }^{\circledR}$ reagent (Invitrogen; Thermo Fisher Scientific, Inc.). The extracted RNA was then reverse transcribed to obtain stable cDNA as follows: $37^{\circ} \mathrm{C}$ for $15 \mathrm{~min}, 85^{\circ} \mathrm{C}$ for $5 \mathrm{sec}, 4^{\circ} \mathrm{C}$. RT primers, including Oligo dT primer and random hexamer primers, were used to generate cDNA with the PrimeScript ${ }^{\mathrm{TM}} \mathrm{RT}$ reagent kit with gDNA Eraser (Takara Bio, Inc.). The ABI 7500 real-time PCR system (Applied Biosystems; Thermo Fisher Scientific, Inc.) was used to amplify the specific PCR products and analyze the threshold cycle number (Cq value) with $\mathrm{TB}$ Green Premix Ex Taq kit from Takara Bio, Inc. The thermocycling conditions as follows: $95^{\circ} \mathrm{C}$ for $30 \mathrm{sec}$, followed by 40 cycles of $95^{\circ} \mathrm{C}$ for $5 \mathrm{sec}$ and $60^{\circ} \mathrm{C}$ for $20 \mathrm{sec}$. The primers for the amplification of Bax, Bcl-2 and GAPDH mRNA were designed and synthesized by Sangon Biotech Co., Ltd., as follows: Bax forward, 5'-AGGACGCATCCACCAAGAAG-3' and reverse, 5'-CAGTTGAAGTTGCCGTCTGC-3'; Bcl-2 forward, 5'-TGGCCTTCTTTGAGTTCGGT-3' and reverse, 5'-GATGCCGGTTCAGGTACTCA-3'; and GAPDH forward, 5'-GGGTCCCAGCTTAGGTTCATC-3' and reverse, 5'-TGAGGTCAATGAAGGGGTCG-3'. GAPDH was used as an internal standard. The qPCR results were normalized to the $\mathrm{Cq}$ value of GAPDH from the same sample, and the $2^{-\Delta \Delta \mathrm{Cq}}(22)$ method was used to calculate the fold change of each gene expression. The amplification reaction for each sample was repeated three times (23). A non-template control was included in each experiment.

Statistical analysis. SPSS 20.0 (version 20.0; IBM Corp.) was used for data analysis. Measurement data are presented as the mean $\pm \mathrm{SD}(\mathrm{n}=3)$, and one-way ANOVA was performed among multiple groups. When meeting the homogeneity of variance, the data were subsequently analyzed with a Dunnett's T3 test. $\mathrm{P}<0.05$ was considered to indicate a statistically significant difference.

\section{Results}

Effect of DHA on MeHg-induced PC12 cell viability. PC12 cells were treated with DHA $(5,10,20,40$ or $80 \mu \mathrm{mol} / \mathrm{l})$ for $24 \mathrm{~h}$ to select the appropriate concentration. In addition, the appropriate $\mathrm{MeHg}$ concentration was screened; PC12 cells were treated with $\mathrm{MeHg}(1.25,2.5,5,10$ and $20 \mu \mathrm{mol} / \mathrm{l})$ for 24, 48 and $72 \mathrm{~h}$. As presented in Fig. 1A, compared with the untreated control group, cell viability was significantly decreased in the $2.5 \mu \mathrm{mol} / 1 \mathrm{MeHg}$ group treated for $48 \mathrm{~h}$. Moreover, it was revealed that treatment with 5 and 10 DHA increased cell viability (Fig. 1B). According to the principle of minimizing the dose and maximizing the curative effect, treatments with $2.5 \mu \mathrm{mol} / \mathrm{l} \mathrm{MeHg}$ for $48 \mathrm{~h}$, and 10 and $20 \mu \mathrm{mol} / 1 \mathrm{DHA}$ for $24 \mathrm{~h}$ were selected as the conditions for subsequent experiments. The results demonstrated that $\mathrm{MeHg}$ significantly inhibited the viability of PC12 cells, whereas DHA could effectively alleviate this effect, which suggested a significant dose-response relationship (Fig. 1C).

Effect of DHA on MeHg-induced PC12 cell apoptosis. TUNEL staining was conducted to examine the protective effect of DHA on MeHg-induced PC12 cell apoptosis. PC12 cells were treated with $2.5 \mu \mathrm{mol} / 1 \mathrm{MeHg}$ and marked apoptosis was observed; however, the fluorescence intensity of DHA was markedly decreased (Fig. 2). In addition, the results of flow cytometry revealed similar findings, and there was a significant dose-response relationship (Fig. 1D and E).

Effects of DHA and MeHg on the expression levels of apoptosis-associated genes and proteins. To further confirm the mechanism underlying MeHg-induced PC12 cell apoptosis, RT-qPCR and western blotting were performed to observe the changes in the mRNA and protein expression levels of apoptosis-related genes. As presented in Fig. 3, the mRNA and protein expression levels of the anti-apoptosis factor $\mathrm{Bcl}-2$ were significantly inhibited after PC12 cells were treated with MeHg compared with those in the control group (Fig. 3A, D and E). However, pretreatment with DHA could markedly rescue the $\mathrm{MeHg}$-induced decrease in Bcl-2. Notably, it was revealed that the relative $\mathrm{mRNA}$ and protein expression levels of Bax were unchanged in all groups (Fig. 3B, D and F).

The Bcl-2/Bax ratio has an important role in cell survival and apoptosis, with a larger ratio associated with more extensive apoptosis (24). The present study demonstrated that the $\mathrm{Bcl}-2 / \mathrm{Bax}$ ratio was significantly decreased in the $\mathrm{MeHg}$ group compared with that in the control group, and was increased in the DHA $(5,10$ and $20 \mu \mathrm{mol} / \mathrm{l})+\mathrm{MeHg}(2.5 \mu \mathrm{mol} / \mathrm{l})$ group compared with that in the MeHg group (Fig. 3C, D and G).

Effect of DHA on ROS production in PC12 cells. PC12 cells were stained with the DCFH-DA fluorescent probe to examine the DCF fluorescence intensity using a fluorescence microplate reader. Compared with that in the control group, the ROS level was significantly increased in the $\mathrm{MeHg}$ group. After DHA pretreatment, the ROS level was decreased in a dose-dependent manner compared with that in the MeHg group (Fig. 4A).

Effect of DHA on the JNK signaling pathway in MeHg-induced PC12 cells. Western blotting was performed to examine 
A

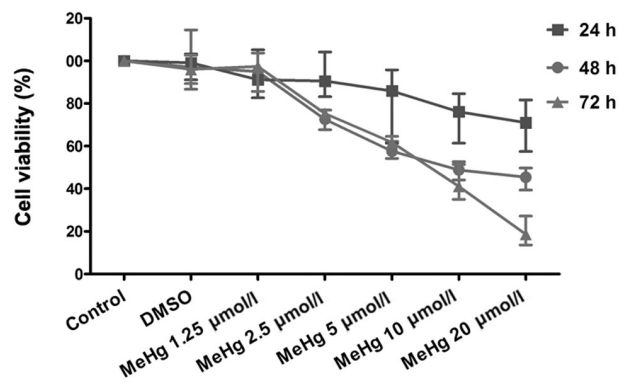

C

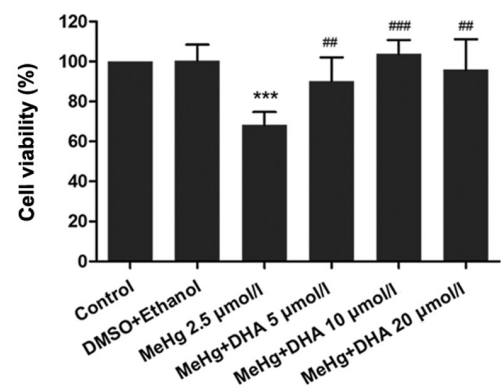

B

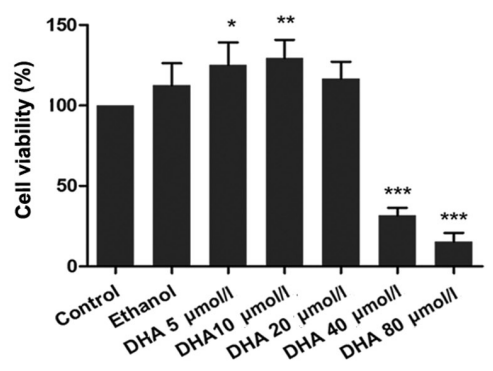

D

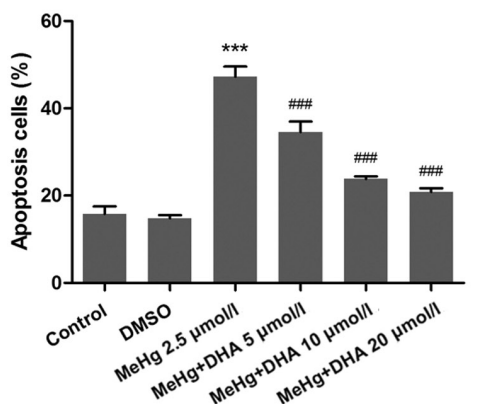

E
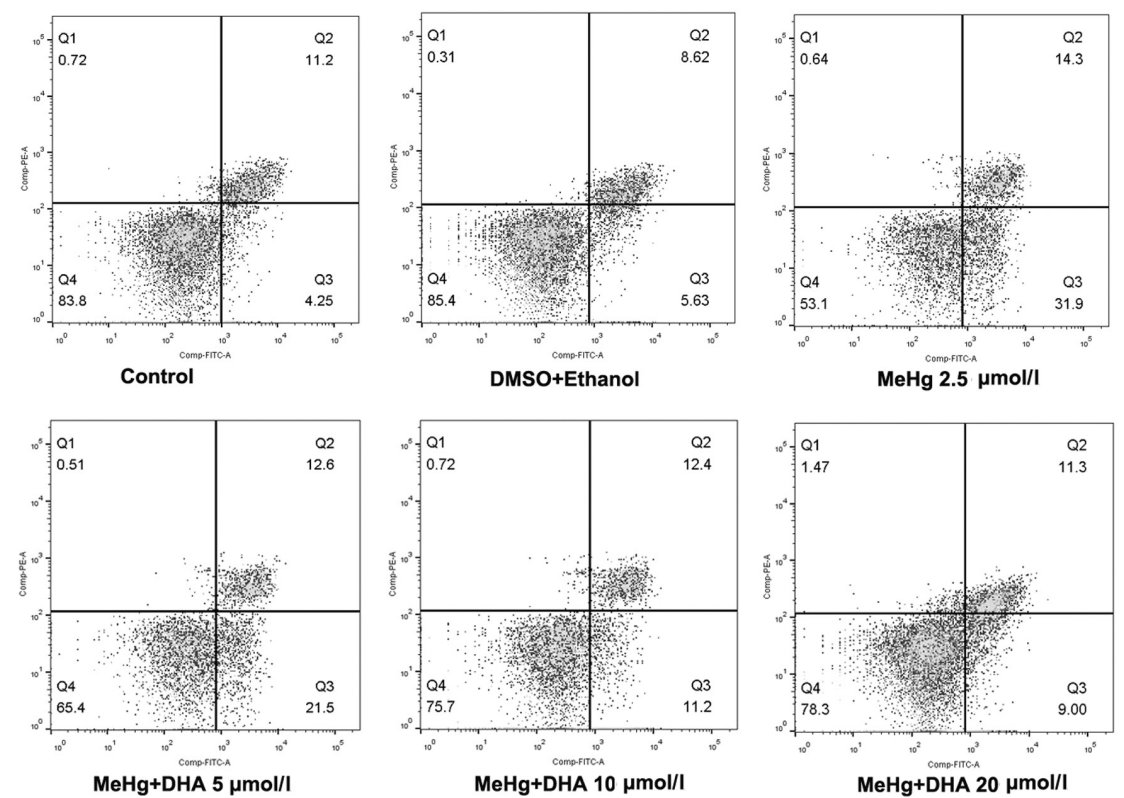

Figure 1. Effects of DHA on MeHg-induced proliferation inhibition and apoptosis of PC12 cells. (A) Changes in cell viability following treatment with MeHg $(1.25,2.5,5,10$ and $20 \mu \mathrm{mol} / \mathrm{l})$ for 24,48 or $72 \mathrm{~h}$. (B) Changes in cell viability following treatment with DHA (5, 10, 20, 40 and $80 \mu \mathrm{mol} / \mathrm{l})$ for $24 \mathrm{~h}$. (C) PC12 cells were treated with $2.5 \mu \mathrm{mol} / \mathrm{l} \mathrm{MeHg}$ for $48 \mathrm{~h}$ and were pretreated with DHA $(5,10$ and $20 \mu \mathrm{mol} / \mathrm{l})$ for $24 \mathrm{~h}$; cell viability was detected using a Cell Counting Kit-8 assay. (D and E) Annexin V-FITC apoptosis detection of PC12 cells pretreated with DHA followed by exposure to MeHg. The apoptosis rate was subsequently analyzed $(\mathrm{n}=3)$. Data are presented as the mean $\pm \mathrm{SD}$. ${ }^{*} \mathrm{P}<0.05,{ }^{* *} \mathrm{P}<0.01$ and ${ }^{* * * *} \mathrm{P}<0.001$ vs. control group; ${ }^{\# \#} \mathrm{P}<0.01$ and ${ }^{\# \# \# *} \mathrm{P}<0.001 \mathrm{vs}$. MeHg group. $\mathrm{MeHg}$, methylmercury; DHA, docosahexaenoic acid.

phosphorylation of the JNK pathway. The results demonstrated that MeHg significantly activated pJNK compared with in the control group; however, DHA significantly inhibited the effect of MeHg (Fig. 4B-D).

Inhibitory effect of NAC on MeHg-induced PC12 cell apoptosis. To further support the results of the mechanistic research, NAC was used as an ROS inhibitor to pretreat PC12 cells to further confirm the relationship between ROS and the JNK pathway. The results demonstrated that, after pretreatment with $500 \mu \mathrm{mol} / 1 \mathrm{NAC}$ at $37^{\circ} \mathrm{C}$ for $30 \mathrm{~min}$, the expression levels of the anti-apoptotic protein $\mathrm{Bcl}-2$ were significantly increased compared with those in the $\mathrm{MeHg}$ group (Fig. 5A and B). Moreover, the expression levels of Bax were not affected (Fig. 5A and C), whereas the Bcl-2/Bax ratio was significantly increased (Fig. 5A and B). In addition, in $\mathrm{PC} 12$ cells exposed to $\mathrm{MeHg}$, the expression levels of pJNK were significantly increased (Fig. 5E-G). By contrast, NAC significantly downregulated the expression levels of pJNK. These findings indicated that ROS may mediate the expression levels of the downstream protein pJNK, and NAC may exert a significant protective effect against $\mathrm{MeHg}$-induced apoptosis. 


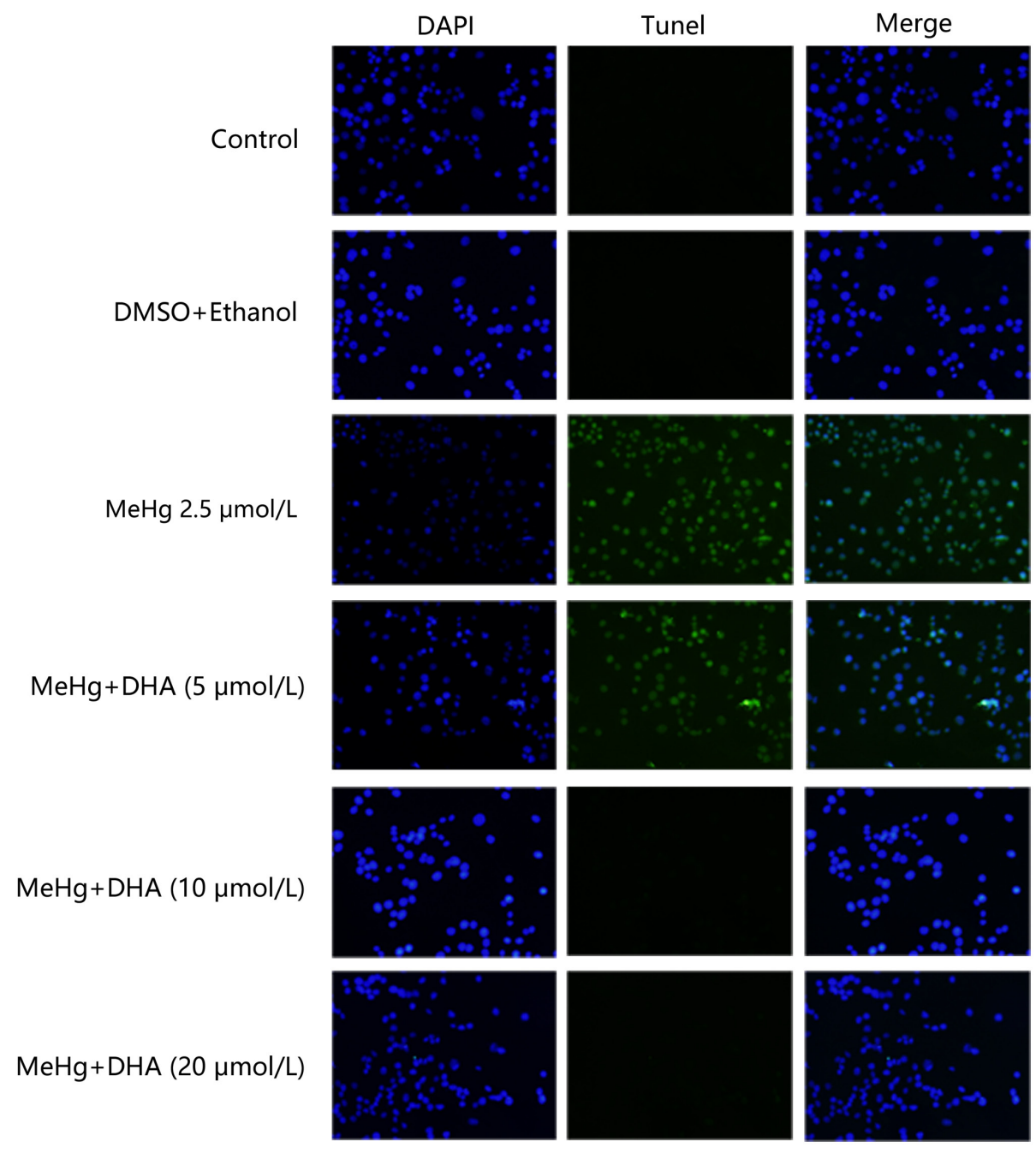

Figure 2. Effects of DHA on MeHg-induced morphological changes of apoptosis of PC12 cells. TUNEL staining was performed using a TUNEL kit to examine the apoptotic rate of PC12 cells that were pretreated with DHA followed by exposure to MeHg. Blue fluorescence represents the cell nucleus, green fluorescence represents the apoptotic cells (magnification, x200). MeHg, methylmercury; DHA, docosahexaenoic acid.

These findings also suggested that DHA may protect PC12 cells from apoptosis induced by $\mathrm{MeHg}$ via antioxidant activity.

\section{Discussion}

Oxidative stress has been widely recognized as an initiator of apoptosis, in which it plays a key role $(25,26)$. Kuo et al (27) reported that oxidative stress caused by ROS may activate the JNK pathway and regulate the transcriptional expression of related downstream genes, leading to apoptosis. Moreover, studies have shown that ROS-induced apoptosis is closely associated with activation of the JNK signaling pathway, which can regulate the expression of apoptosis-related genes and ultimately lead to cell apoptosis (28-30). Therefore, the JNK/ROS signaling pathway was selected as the focus of the mechanistic research in the present study.

$\mathrm{MeHg}$ has been recognized as a highly toxic pollutant in the environment, which is mainly absorbed by humans in the gastrointestinal tract, and easily crosses the blood-brain barrier and the placental barrier, exerting adverse effects on neurodevelopment (31), including IQ reduction and language impairment (32). It has been reported that a low dose of $\mathrm{MeHg}$ may exert a toxic effect on nerve precursor cells (33). In addition, Petroni et al (34) observed that low concentrations of MeHg significantly decreased the viability of SY-SY5Y neuroblastoma cells, resulting in permanent cell damage. As an essential unsaturated fatty acid in humans, DHA has been reported to possess antioxidant and antiapoptotic effects (35). DHA has been demonstrated to be crucial for the development of the nervous system, particularly vision and cognition of infants and young children (36). Therefore, the present study investigated the potential protective effect of DHA against $\mathrm{MeHg}$ poisoning and the possible molecular mechanisms. In the current study, PC12 cells, which are widely applied in neuronal cell models in vitro, were used to identify the mechanism of MeHg-induced PC12 cell apoptosis via the ROS/JNK signaling pathway and to examine the protective role of DHA in this process.

First, the MeHg poisoning model was established in vitro. DHA pretreatment efficiently rescued $\mathrm{MeHg}$-induced cell viability inhibition and apoptosis. Notably, $\mathrm{MeHg}$ at $1.25 \mu \mathrm{mol} / \mathrm{l}$ had no toxic effect on PC12 cells, and it was suggested that low-dose $\mathrm{MeHg}$ may initiate the toxic excitatory effect of cells and trigger a series of repair activation mechanisms, which was 
A

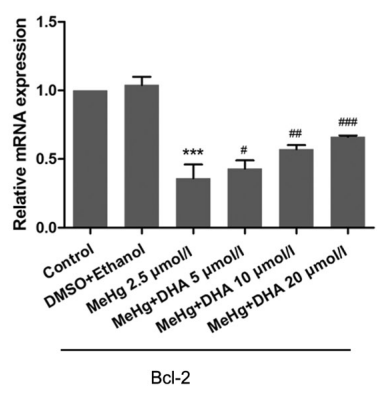

D

cl-2

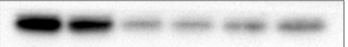

Bax

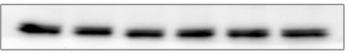

GAPDH

$\mathrm{MeHg}(\mu \mathrm{mol} / \mathrm{l})$

DHA $(\mu \mathrm{mol} / \mathrm{l})$

DMSO+Ethanol
B

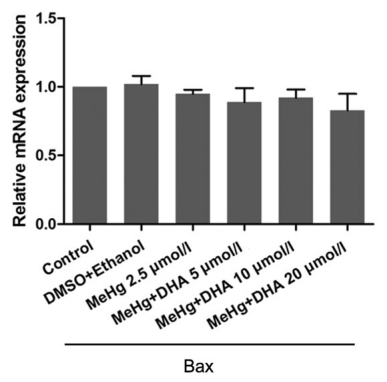

E
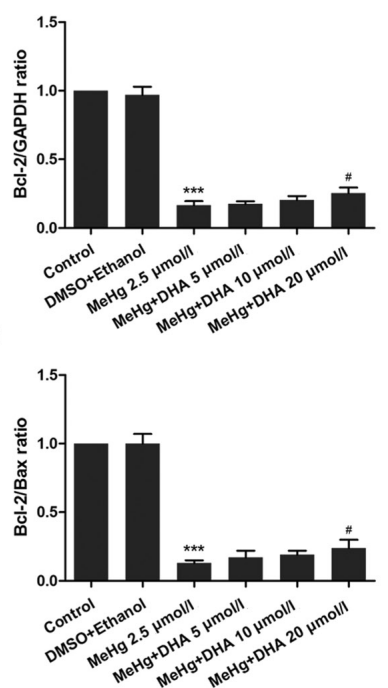

C

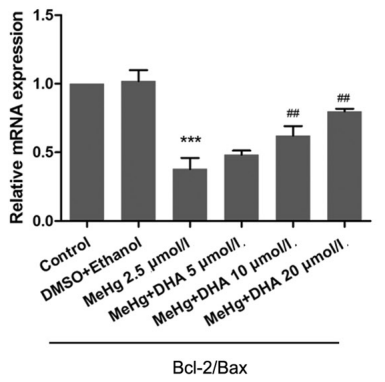

F

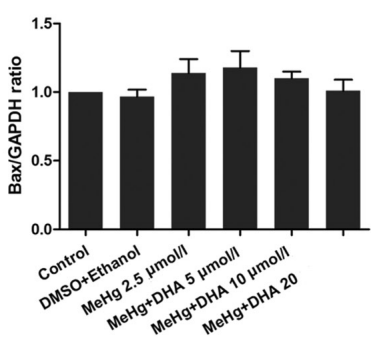

Figure 3. Effects of DHA on MeHg-induced changes in the mRNA and protein expression levels of Bcl-2 and Bax. Reverse transcription-quantitative PCR was used to detect changes in the mRNA expression levels of (A) Bcl-2 and (B) Bax, and (C) Bcl-2/Bax ratio in PC12 cells pretreated with DHA (5, 10 and $20 \mu \mathrm{mol} / \mathrm{l}$ ) followed by exposure to $2.5 \mu \mathrm{mol} / 1 \mathrm{MeHg}$ for $48 \mathrm{~h}$. Relative expression levels were normalized to the corresponding GAPDH levels. (D) Western blotting demonstrated the dynamic changes in the protein expression levels of (E) Bcl-2 and (F) Bax, and (G) Bcl-2/Bax ratio in PC12 cells pretreated with DHA $(5,10$ and $20 \mu \mathrm{mol} / 1)$ followed by exposure to $2.5 \mu \mathrm{mol} / 1 \mathrm{MeHg}$ for $48 \mathrm{~h}$. Protein band intensity was analyzed after normalization to the corresponding GAPDH levels, and the relative ratios were analyzed after normalization to the corresponding control group. Data are presented as the mean $\pm \mathrm{SD}, \mathrm{n}=3$. ${ }^{* * *} \mathrm{P}<0.001$ vs. control group; ${ }^{\# \mathrm{P}}<0.05,{ }^{\# \#} \mathrm{P}<0.01$ and ${ }^{\# \# \#} \mathrm{P}<0.001$ vs. MeHg group. MeHg, methylmercury; DHA, docosahexaenoic acid.

A

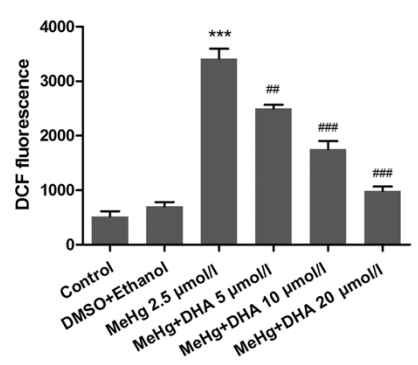

B

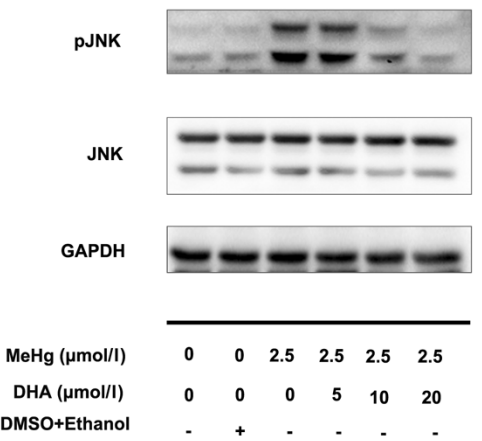

C

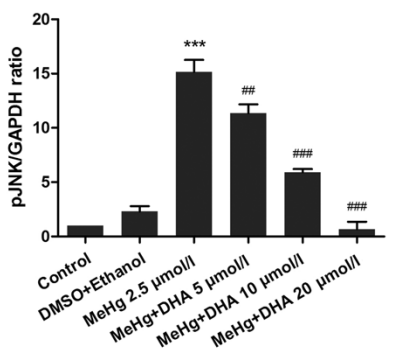

D

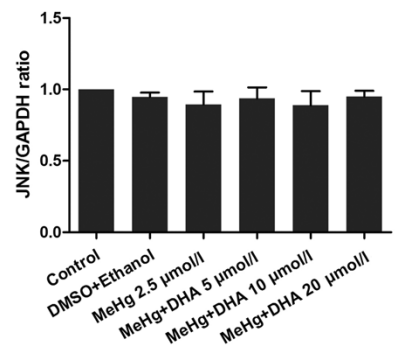

Figure 4. Effects of DHA on MeHg-induced changes in ROS levels, and JNK and pJNK expression. (A) A fluorescence microplate reader was used to analyze the changes in ROS levels in PC12 cells pretreated with DHA (5, 10 and $20 \mu \mathrm{mol} / 1)$ followed by exposure to $2.5 \mu \mathrm{mol} / 1 \mathrm{MeHg}$. DCF fluorescence intensity was recorded. (B) Western blotting demonstrated the dynamic changes in (C) JNK and (D) pJNK expression levels in PC12 cells pretreated with DHA (5, 10 and $20 \mu \mathrm{mol} / \mathrm{l}$ ) followed by exposure to $2.5 \mu \mathrm{mol} / 1 \mathrm{MeHg}$ for $48 \mathrm{~h}$. Protein band intensity was analyzed after normalization to the corresponding GAPDH levels, and the relative ratios were analyzed after normalization to the corresponding control group. Double bands indicate different isoforms. Data are presented as the mean $\pm \mathrm{SD}, \mathrm{n}=3 .{ }^{* * * *} \mathrm{P}<0.001$ vs. control group; ${ }^{\# \#} \mathrm{P}<0.01$ and ${ }^{\# \# \#} \mathrm{P}<0.001$ vs. MeHg group. MeHg, methylmercury; DHA, docosahexaenoic acid; p, phosphorylated; ROS, reactive oxygen species.

verified in the research of Tan et al (37). In addition, it is well known that DHA has significant antioxidant effects; however, the present study revealed that PC12 cell survival was reduced following treatment with high concentrations of DHA, which was consistent with the finding of Iuchi et al (38). In addition, Srikanth et al (39) revealed that higher concentrations of DHA 
A

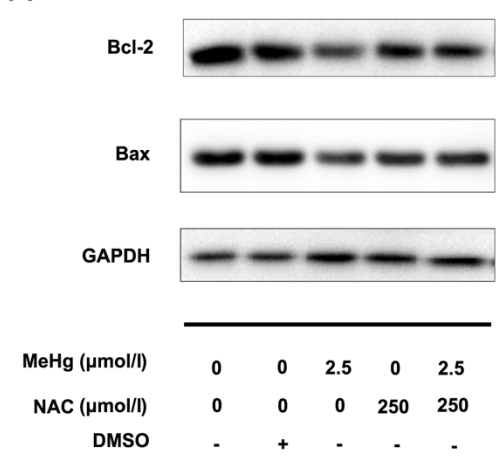

E

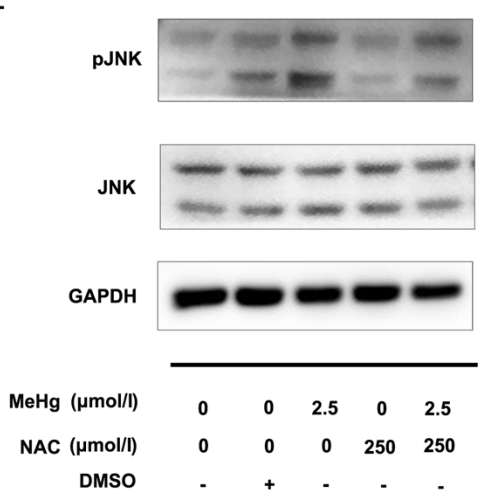

B

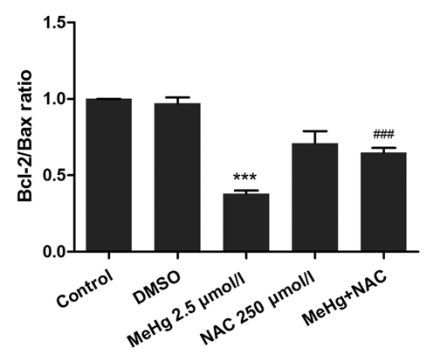

$\mathrm{F}$

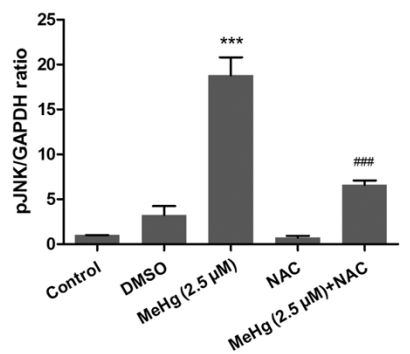

C

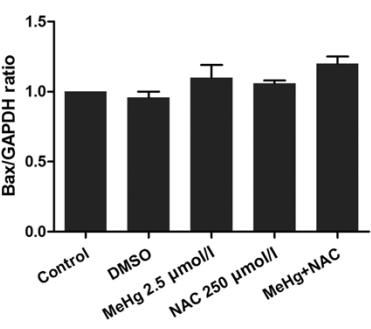

D

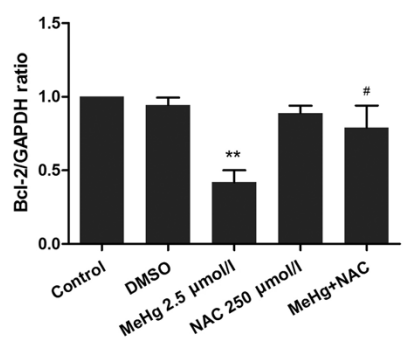

Figure 5. Effects of NAC on MeHg-induced changes in the expression levels of apoptosis-related proteins in PC12 cells. (A) Western blotting demonstrated the dynamic changes in (B) Bcl-2/Bax ratio, and the protein expression levels of (C) Bax and (D) Bcl-2 in PC12 cells pretreated with $250 \mu \mathrm{mol} / 1 \mathrm{NAC}$ for 60 min followed by exposure to $2.5 \mu \mathrm{mol} / 1 \mathrm{MeHg}$ for $48 \mathrm{~h}$. (E) Western blotting demonstrated the dynamic changes in the protein expression levels of (F) pJNK and (G) JNK in PC12 cells pretreated with $250 \mu \mathrm{mol} / 1 \mathrm{NAC}$ for $60 \mathrm{~min}$ followed by exposure to $2.5 \mu \mathrm{mol} / 1 \mathrm{MeHg}$ for 48 h. Protein band intensity was analyzed after normalization to the corresponding GAPDH levels, and the relative ratios were analyzed after normalization to the corresponding control group. Data are presented as the mean $\pm \mathrm{SD}, \mathrm{n}=3 .{ }^{* * *} \mathrm{P}<0.01$ and ${ }^{* * *} \mathrm{P}<0.001$ vs. control group; ${ }^{*} \mathrm{P}<0.05$ and ${ }^{\# \# \#} \mathrm{P}<0.001$ vs. MeHg group. MeHg, methylmercury; DHA, docosahexaenoic acid; p, phosphorylated; NAC, N-acetyl-1-cysteine.

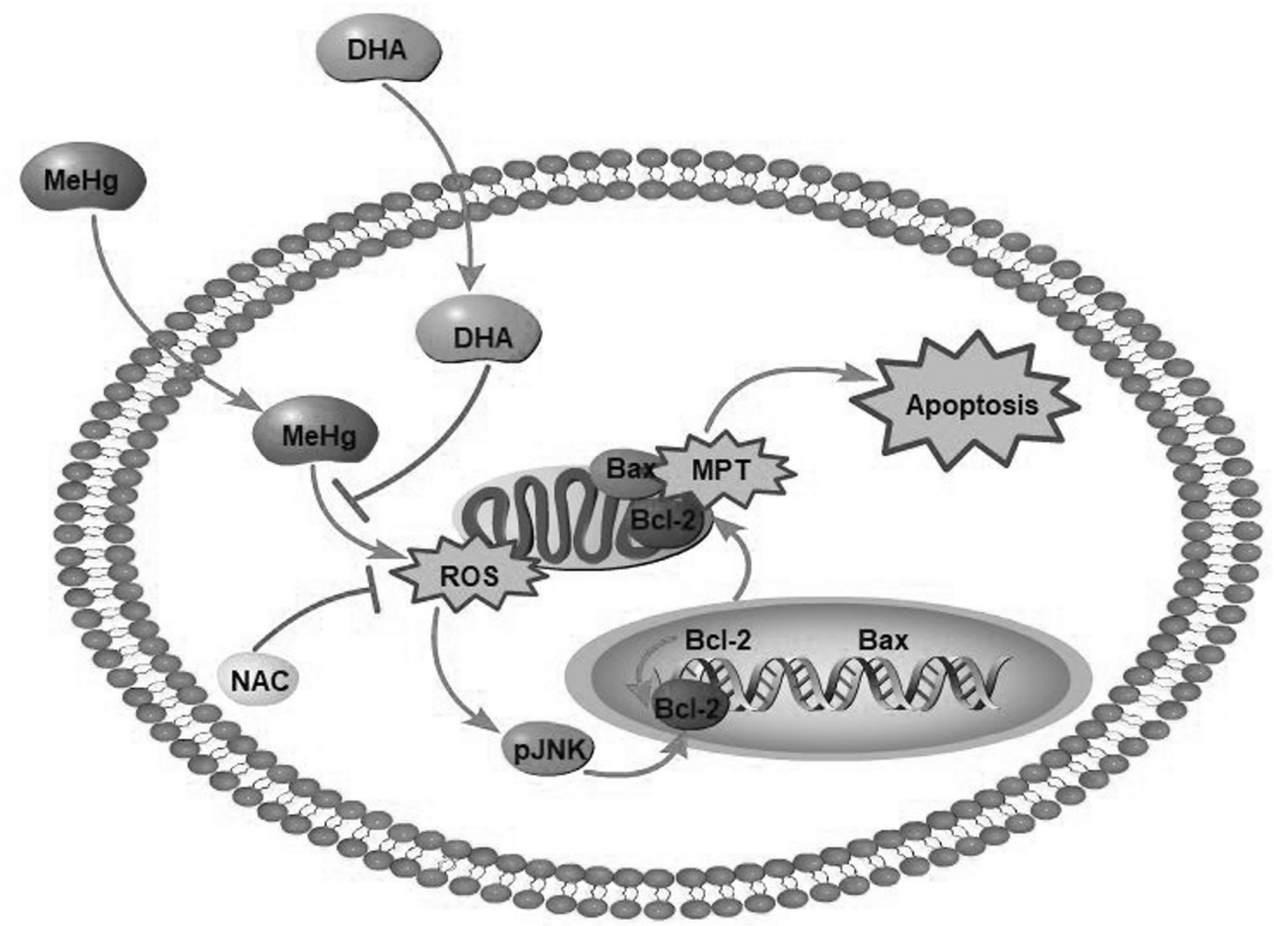

Figure 6. Schematic diagram of protective effects of DHA against MeHg-induced apoptosis mediated by ROS via the JNK signaling pathway MeHg, methylmercury; DHA, docosahexaenoic acid; ROS, reactive oxygen species; p, phosphorylated; NAC, N-acetyl-1-cysteine; MPT, mitochondrial phosphate transporter. 
induced profound cell swelling and a reduction in viability, which was accompanied by increased expression levels of inflammatory cytokine and lipoxygenase genes, activation of caspase- 1 activity and release of IL1 $\beta$, indicating that cells were undergoing a proinflammatory cell death program known as pyroptosis; this may be one of the reasons that high concentrations of DHA become toxic.

A number of studies have demonstrated that oxidative stress may serve an important role in $\mathrm{MeHg}$-induced apoptosis $(40,41)$. Therefore, the present study examined the effect of MeHg and DHA on intracellular ROS levels to evaluate the potential mechanism underlying the effects of DHA on MeHg-induced apoptosis of PC12 cells. The results demonstrated that $\mathrm{MeHg}$ significantly increased the levels of ROS, whereas DHA effectively inhibited MeHg-induced oxidative injury to PC12 cells. As members of the MAPK superfamily, JNKs serve a crucial role in cell survival and apoptosis $(42,43)$. Therefore, the protective effects of DHA on MeHg-induced apoptosis at the level of the JNK signaling pathway were further investigated. The results demonstrated that the JNK signaling pathway was markedly activated and that the expression of pJNK was significantly increased after PC12 cells were exposed to MeHg.

The mitochondrial pathway is the most important pathway that mediates cell apoptosis. The change in mitochondrial outer membrane permeability (MOMP) is considered to be the main switch of the mitochondrial apoptosis pathway, and MOMP is strictly regulated by the $\mathrm{Bcl}-2$ family and promotes apoptosis (44). Some members of the Bcl-2 family, such as Bax, can directly promote changes in MOMP. When apoptosis is induced, Bax migrates from the cytosol to the mitochondria and nuclear membrane, and initiates the caspase cascade via cytochrome $c$ and second mitochondria-derived activator caspase pathways (45). The present study demonstrated that the mRNA and protein expression levels of anti-apoptotic Bcl-2 were almost completely inhibited by $\mathrm{MeHg}$; however, there was no significant change in the mRNA or protein expression levels of pro-apoptotic Bax, which was similar to other research findings (46). Notably, Hou et al (47) revealed that Bax may not always be a potent inducer of apoptosis in tumor cells. It has been reported that the Bcl-2/Bax ratio is essential for determining whether cells undergo apoptosis, which is consistent with the current study (24). Additionally, the present study revealed that restoration of Bcl-2 transcription by DHA seemed to be more obvious than that of $\mathrm{Bcl}-2$ protein expression, which may be related to the length of administration time. This phenomenon was also reported in a previous study (28).

To further confirm the protective mechanism of DHA and to elucidate the relationship between ROS and signaling pathways, NAC, an efficient ROS scavenger, was used to pretreat cells in the present study. The results demonstrated that all of the adverse effects of $\mathrm{MeHg}$ were improved; notably, NAC pretreatment inhibited JNK signaling, and increased the expression levels of the anti-apoptosis protein Bcl-2 and the ratio of Bcl-2 to Bax. Therefore, these results suggested that DHA may ameliorate MeHg-induced apoptosis via the ROS-regulated JNK signaling pathway.

In conclusion, MeHg significantly increased the ROS content in PC12 cells and induced oxidative stress, whereas
DHA effectively decreased levels of intracellular ROS to relieve oxidative stress-induced PC12 cell apoptosis (Fig. 6). Moreover, DHA may reverse the MeHg-induced adverse effects, including the elevated phosphorylation of JNK, and decreased mRNA and protein expression levels of anti-apoptotic $\mathrm{Bcl}-2$. To the best of our knowledge, the present study was the first to attempt to elucidate the protective effects of DHA against MeHg-induced PC12 cell apoptosis via the ROS/JNK signaling pathway, which may provide a theoretical basis for the treatment of $\mathrm{MeHg}$ poisoning. Our future studies will focus on $\mathrm{MeHg}$ target gene prediction by full transcriptome sequencing of samples, in order to further elucidate the protective mechanism of DHA on MeHg-induced apoptosis of PC12 cells.

\section{Acknowledgements}

Not applicable.

\section{Funding}

The present study was supported by grants from the National Science Foundation of China (grant no. 81973062) and the National Key R\&D Program of China (grant no. 2017YFC1600500).

\section{Availability of data and materials}

The datasets generated and/or analyzed during the current study are not publicly available due to privacy of laboratory content but are available from the corresponding author on reasonable request.

\section{Authors' contributions}

CY made substantial contributions to the conception and design of the study, analysis and interpretation of data, acquisition of funding and supervision of the research. HZ and SW performed the experiments. YW, AL and $\mathrm{CH}$ made substantial contributions to the analysis and interpretation of data. $\mathrm{HZ}$ and SW confirm the authenticity of all the raw data. All authors read and approved the final manuscript.

\section{Ethics approval and consent to participate}

Not applicable.

\section{Patient consent for publication}

Not applicable.

\section{Competing interests}

The authors declare that they have no competing interests.

\section{References}

1. Jacobs S, Sioen I, Jacxsens L, Domingo JL, Sloth JJ, Marques A and Verbeke W: Risk assessment of methylmercury in five European countries considering the national seafood consumption patterns. Food Chem Toxicol 104: 26-34, 2017. 
2. Hylander LD: Global Mercury Pollution and its Expected Decrease after a Mercury Trade Ban. Water Air Soil Pollut 125: 331-344, 2001.

3. Borowska S and Brzóska MM: Metals in cosmetics: Implications for human health. J Appl Toxicol 35: 551-572, 2015.

4. Kim W, Kim DW, Yoo DY, Jung HY, Kim JW, Kim DW, Choi JH, Moon SM, Yoon YS and Hwang IK: Antioxidant effects of Dendropanax morbifera Léveille extract in the hippocampus of mercury-exposed rats. BMC Complement Altern Med 15: 247, 2015.

5. Clarkson TW, Magos L and Myers GJ: The toxicology of mercury - current exposures and clinical manifestations. N Eng J Med 349: 1731-1737, 2003.

6. Syversen T and Kaur P: The toxicology of mercury and its compounds. J Trace Elem Med Biol 26: 215-226, 2012.

7. Bellinger DC, Devleesschauwer B, O'Leary K and Gibb HJ: Global burden of intellectual disability resulting from prenata exposure to methylmercury, 2015. Environ Res 170: 416-421, 2019.

8. Sheehan MC, Burke TA, Navas-Acien A, Breysse PN, McGready $\mathrm{J}$ and Fox MA: Global methylmercury exposure from seafood consumption and risk of developmental neurotoxicity: A systematic review. Bull World Health Organ 92: F254-F269, 2014.

9. Ke T, Gonçalves FM, Gonçalves CL, dos Santos AA, Rocha JBT, Farina M, Skalny A, Tsatsakis A, Bowman AB and Aschner M: Post-translational modifications in MeHg-induced neurotoxicity. Biochim Biophys Acta Mol Basis Dis 1865: 2068-2081, 2019.

10. Ying Z, Chen K, Zheng L, Wu Y, Li L, Wang R, Long Q, Yang L, Guo J, Yao D, et al: Transient Activation of Mitoflashes Modulates Nanog at the Early Phase of Somatic Cell Reprogramming. Cell Metab 23: 220-226, 2016.

11. Yu L, Liu Z, Qiu L, Hao L and Guo J: Ipatasertib sensitizes colon cancer cells to TRAIL-induced apoptosis through ROS-mediated caspase activation. Biochem Biophys Res Commun 519: 812-818, 2019.

12. Tan BL, Norhaizan ME and Chan LC: ROS-Mediated Mitochondrial Pathway is Required for Manilkara Zapota (L.) P. Royen Leaf Methanol Extract Inducing Apoptosis in the Modulation of Caspase Activation and EGFR/NF-K B Activities of HeLa Human Cervical Cancer Cells. Evid Based Complement Alternat Med 2018: 6578648, 2018.

13. Mangali S, Bhat A, Udumula MP, Dhar I, Sriram D and Dhar A: Inhibition of protein kinase $\mathrm{R}$ protects against palmitic acid-induced inflammation, oxidative stress, and apoptosis through the JNK/NF- $\kappa \mathrm{B} / \mathrm{NLRP} 3$ pathway in cultured $\mathrm{H} 9 \mathrm{C} 2$ cardiomyocytes. J Cell Biochem 120: 3651-3663, 2019.

14. Chen Y, Feng X, Hu X, Sha J, Li B, Zhang H and Fan $\mathrm{H}$ : Dexmedetomidine Ameliorates Acute Stress-Induced Kidney Injury by Attenuating Oxidative Stress and Apoptosis through Inhibition of the ROS/JNK Signaling Pathway. Oxid Med Cell Longev 2018: 4035310, 2018.

15. Niu S-L, Mitchell DC, Lim S-Y, Wen ZM, Kim HY, Salem N Jr and Litman BJ: Reduced G protein-coupled signaling efficiency in retinal rod outer segments in response to n-3 fatty acid deficiency. J Biol Chem 279: 31098-31104, 2004.

16. Oken E, Wright RO, Kleinman KP, Bellinger D Amarasiriwardena $\mathrm{CJ}, \mathrm{Hu} \mathrm{H}$, Rich-Edwards $\mathrm{JW}$ and Gillman MW: Maternal fish consumption, hair mercury, and infant cognition in a U.S. Cohort. Environ Health Perspect 113: 1376-1380, 2005.

17. Oken E, Østerdal ML, Gillman MW,Knudsen VK,Halldorsson TI Strøm M, Bellinger DC, Hadders-Algra M, Michaelsen KF and Olsen SF: Associations of maternal fish intake during pregnancy and breastfeeding duration with attainment of developmental milestones in early childhood: A study from the Danish National Birth Cohort. Am J Clin Nutr 88: 789-796, 2008.

18. Cardoso C, Bernardo I, Bandarra NM, Louro Martins L and Afonso C: Portuguese preschool children: Benefit (EPA+DHA and $\mathrm{Se}$ ) and risk (MeHg) assessment through the consumption of selected fish species. Food Chem Toxicol 115: 306-314, 2018.

19. Nøstbakken OJ, Bredal IL, Olsvik PA, Huang TS and Torstensen BE: Effect of marine omega 3 fatty acids on methylmercury-induced toxicity in fish and mammalian cells in vitro. J Biomed Biotechnol 2012: 417652, 2012.

20. Kaur P, Heggland I, Aschner M and Syversen T: Docosahexaenoic acid may act as a neuroprotector for methylmercury-induced neurotoxicity in primary neural cell cultures. Neurotoxicology 29: 978-987, 2008
21. Takanezawa Y, Nakamura R, Hamaguchi M, Yamamoto K, Sone Y, Uraguchi S and Kiyono M: Docosahexaenoic acid enhances methylmercury-induced endoplasmic reticulum stress and cell death and eicosapentaenoic acid potentially attenuates these effects in mouse embryonic fibroblasts. Toxicol Lett 306 : 35-42, 2019.

22. Livak KJ and Schmittgen TD: Analysis of relative gene expression data using real-time quantitative PCR and the 2(- $\Delta \Delta$ C(T)) Method. Methods 25: 402-408, 2001.

23. Huang $Y$, Huang $H$, Wang $S$, Chen $F$ and Zheng $G$ : Dehydrocorydaline inhibits the tumorigenesis of breast cancer MDA MB 231 cells. Mol Med Rep 22: 43-50, 2020.

24. Zhao L, Gu Q, Xiang L, Dong X, Li H, Ni J, Wan L, Cai G and Chen G: Curcumin inhibits apoptosis by modulating $\mathrm{Bax} / \mathrm{Bcl}-2$ expression and alleviates oxidative stress in testes of streptozotocin-induced diabetic rats. Ther Clin Risk Manag 13: 1099-1105, 2017.

25. de Angelis C, Galdiero M, Pivonello C, Salzano C, Gianfrilli D, Piscitelli P, Lenzi A, Colao A and Pivonello R: The environment and male reproduction: The effect of cadmium exposure on reproductive function and its implication in fertility. Reprod Toxicol 73: 105-127, 2017.

26. Zhang X, Wang M, Teng S, Wang D, Li X, Wang X, Liao W and Wang D: Indolyl-chalcone derivatives induce hepatocellular carcinoma cells apoptosis through oxidative stress related mitochondrial pathway in vitro and in vivo. Chem Biol Interact 293: 61-69, 2018

27. Kuo LM, Chen PJ, Sung PJ, Chang YC, Ho CT, Wu YH and Hwang TL: The Bioactive Extract of Pinnigorgia sp. Induces Apoptosis of Hepatic Stellate Cells viaROS-ERK/JNK-Caspase-3 Signaling. Mar Drugs 16:19, 2018.

28. Ren X, Wang S, Zhang C, Hu X, Zhou L, Li Y and Xu L: Selenium ameliorates cadmium-induced mouse leydig TM3 cell apoptosis via inhibiting the ROS/JNK /c-jun signaling pathway. Ecotoxicol Environ Saf 192: 110266, 2020

29. Chen X, Wu W, Gong B, Hou L, Dong X, Xu C, Zhao R, Yu Q, Zhou Z, Huang S, et al: Metformin attenuates cadmium-induced neuronal apoptosis in vitro via blocking ROS-dependent PP5/AMPK-JNK signaling pathway. Neuropharmacology 175: $108065,2020$.

30. Wang Z, Yu K, Hu Y, Su F, Gao Z, Hu T, Yang Y, Cao X and Qian F: Schisantherin A induces cell apoptosis through ROS/JNK signaling pathway in human gastric cancer cells. Biochem Pharmacol 173: 113673, 2020.

31. Zareba G, Cernichiari E, Hojo R, Nitt SM, Weiss B, Mumtaz MM Jones DE and Clarkson TW: Thimerosal distribution and metabolism in neonatal mice: Comparison with methyl mercury. J Appl Toxicol 27: 511-518, 2007.

32. Poling A and LeSage M: Evaluating psychotropic drugs in people with mental retardation: Where are the social validity data? Am J Ment Retard 100: 193-200, 1995.

33. Watanabe J, Nakamachi T, Ohtaki H, Naganuma A, Shioda S and Nakajo S: Low dose of methylmercury $(\mathrm{MeHg})$ exposure induces caspase mediated-apoptosis in cultured neural progenitor cells J Toxicol Sci 38: 931-935, 2013

34. Petroni D, Tsai J, Agrawal K, Mondal D and George W: Low-dose methylmercury-induced oxidative stress, cytotoxicity, and tau-hyperphosphorylation in human neuroblastoma (SH-SY5Y) cells. Environ Toxicol 27: 549-555, 2012.

35. Calder PC: Omega-3 polyunsaturated fatty acids and inflammatory processes: nutrition or pharmacology? Br J Clin Pharmacol 75: 645-662, 2013.

36. Kuratko CN, Barrett EC, Nelson EB and Salem N Jr: The relationship of docosahexaenoic acid (DHA) with learning and behavior in healthy children: a review. Nutrients 5: 2777-2810,2013.

37. Tan Q, Zhang M, Geng L, Xia Z, Li C, Usman M, Du Y, Wei L and $\mathrm{Bi} \mathrm{H}$ : Hormesis of methylmercury-human serum albumin conjugate on N9 microglia via ERK/MAPKs and STAT3 signaling pathways. Toxicol Appl Pharmacol 362: 59-66, 2019.

38. Iuchi K, Ema M, Suzuki M, Yokoyama $\mathrm{C}$ and Hisatomi $\mathrm{H}$ Oxidized unsaturated fatty acids induce apoptotic cell death in cultured cells. Mol Med Rep 19: 2767-2773, 2019.

39. Srikanth M, Chandrasaharan K, Zhao X, Chayaburakul K, Ong W-Y and Herr DR: Metabolism of Docosahexaenoic Acid (DHA) Induces Pyroptosis in BV-2 Microglial Cells. Neuromolecular Med 20: 504-514, 2018.

40. Xue D-F, Pan S-T, Huang G and Qiu J-X: ROS enhances the cytotoxicity of cisplatin by inducing apoptosis and autophagy in tongue squamous cell carcinoma cells. Int J Biochem Cell Biol 122: 105732, 2020 
41. Hassani S, Ghaffari P, Chahardouli B, Alimoghaddam K, Ghavamzadeh A, Alizadeh S and Ghaffari SH: Disulfiram/copper causes ROS levels alteration, cell cycle inhibition, and apoptosis in acute myeloid leukaemia cell lines with modulation in the expression of related genes. Biomed Pharmacother 99: 561-569, 2018.

42. Liu Z, Li C, Wu G, Li W, Zhang X, Zhou J, Zhang L, Tao J, Shen $\mathrm{M}$ and Liu H: Involvement of JNK/FOXO1 pathway in apoptosis induced by severe hypoxia in porcine granulosa cells. Theriogenology 154: 120-127, 2020.

43. Zhang Y, Li Y, Ma P, Chen J and Xie W: Ficus carica leaves extract inhibited pancreatic $\beta$-cell apoptosis by inhibiting AMPK/JNK/caspase-3 signaling pathway and antioxidation. Biomed Pharmacother 122: 109689, 2020.

44. Kalkavan H and Green DR: MOMP, cell suicide as a BCL-2 family business. Cell Death Differ 25: 46-55, 2018.
45. Qi H, Jiang Y, Yin Z, Jiang K, Li L and Shuai J: Optimal pathways for the assembly of the Apaf-1·cytochrome $c$ complex into apoptosome. Phys Chem Chem Phys 20: 1964-1973, 2018.

46. Pouraminaei M, Mirzaiey MR, Khoshdel A, Hajizadeh MR, Mahmoodi M and Fahmidehkar MA: The effect of Cressa Cretica hydroalcoholic extract on apoptosis and the expression of Bcl2, Bax and P53 genes in hepatoma cell line HepG2. Gene Rep 20: 100692, 2020

47. Hou D, Che Z, Chen P, Zhang W, Chu Y, Yang D and Liu J: Suppression of AURKA alleviates p27 inhibition on Bax cleavage and induces more intensive apoptosis in gastric cancer. Cell Death Dis 9: 781, 2018.

This work is licensed under a Creative Commons Attribution-NonCommercial-NoDerivatives 4.0 International (CC BY-NC-ND 4.0) License. 